\title{
Mersin İlinin Farkıı İlçelerinde Kurulabilecek Rüzgar Enerjisi Santrallerinin RETScreen Programı ile Fizibilite Analizleri ve Karşılaştırılmaları
}

\author{
Bengi GÖZMEN ŞANLI*, Alper GÜNÖZ
}

Mersin Üniversitesi, Mühendislik Fakültesi, Makine Mühendisliği Bölümü, Mersin, Türkiye

Geliş / Received: 20/05/2018, Kabul / Accepted: 08/10/2018

\section{Öz}

Son yıllarda hızla artan enerji ihtiyacını karşılamak üzere yenilenebilir enerji kaynaklarına yönelim artmışıtır ve özellikle dünya genelinde yüksek potansiyele sahip olan rüzgar enerjisi tercih edilmektedir. Bu çalı̧̧mada Mersin'in Mut ve Gülnar ilçeleri için RETScreen programı kullanılarak farklı güçlerde $(0,8,4$ ve $8 \mathrm{MW})$ kurulacak olan rüzgar enerji santrali (RES) yatırımlarının fizibilite analizi yapılmış ve birbirleriyle karşılaştırılmıştır. Bu amaçla $0,8,4$ ve $8 \mathrm{MW}$ kapasiteli rüzgar enerji santrali projeleri değerlendirilerek Mut ve Gülnar ilçeleri için geri ödeme süreleri tespit edilmiştir. Mut'un yıllık ortalama rüzgar hızı değerinin Gülnar'dan daha yüksek olması ve projelerin kendilerini geri ödeme süreleri dikkate alındığında yapılacak yatırım yerinin Mut olarak seçilmesi daha uygun görülmüştür. Mut için tasarlanan; 1 adet türbin kullanılacak olan rüzgar enerji santralinin 5 yılda, 5 adet türbin kullanılacak olanın 3,5 yılda, 10 adet türbin kullanılacak olanın 3 yılda kendini amorti edebileceği belirlenmiştir. Ekonomik açıdan rüzgar enerji santrali yatırımlarının banka faizi geliri dikkate alındığında yatırımcılar için tercih edilebilir bir proje olduğu saptanmıştır.

Anahtar Kelimeler: Gülnar, Mut, RETScreen, Rüzgar Enerjisi

\section{Feasibility Analyses and Comparisons of Wind Power Plants Located in Different Regions of Mersin by Using RETScreen Program}

\begin{abstract}
In recent years, the trend towards renewable energy sources has increased to meet the rapidly growing energy demand and especially wind energy, which has a high potential around the world, is preferred. In this study, feasibility analyses of the wind power plant(RES) investments have been performed for different wind power plant having different capacities (0.8, 4 ve $8 \mathrm{MW}$ ) in Mut-Gülnar, Mersin by using the RETScreen program and they have been compared with each other. The wind power plants having different capacities of $0.8,4$ ve $8 \mathrm{MW}$ in both Mut and Gülnar have been analyzed and repayment period have been determined. Mut should be selected as investment location due to the fact that the average wind speed of Mut is higher than that of Gülnar and repayment period is shorther than that of Gülnar. Moreover, it is determined that the wind power plant having 1 turbine in Mut has a repayment period as 5 years, the wind power plant having 3 turbines has a repayment period as 3.5 years while the power plant having 5 turbines repays the investment for it in three years. In terms of economy, the projects of wind power plant are profitable investment when the bank interest income is considered.
\end{abstract}

Keywords: Gulnar, Mut, RETScreen, Wind Energy

\section{Giriş}

Son yıllarda gelişen teknoloji ve dünya nüfusundaki hızlı artışla birlikte enerji ihtiyacı sürekli olarak artmaktadır. Enerji ihtiyacındaki artış, küresel ısınma ve ekolojik etkiler göz önüne alındığında enerji elde etmek için fosil yakıt kullanımı yerini daha temiz ve doğa dostu yenilenebilir enerji kaynaklarına bırakmaktadır. Fosil yakıtlardan kaynaklanan çevresel kirliliği en aza indirme isteği, Kyoto Protokolü gereğince $\mathrm{CO}_{2}$ ve diğer sera gazı emisyonlarının azaltılması zorunluluğu yenilenebilir enerji kaynaklarının kullanımını mecburi hale getirmiştir (Taşkın, 2013). Kullanımı çok eskilere dayanan rüzgar enerjisi, tüm dünyada en çok kullanılan yenilenebilir enerji kaynaklarından biridir. Türkiye rüzgar enerji potansiyeli bakımından oldukça zengin bir ülkedir. Fakat kullanılabilir rüzgar enerji potansiyeli oldukça düşüktür. Bunun nedeni ise, rüzgar enerji santrallerinin kurulum 
bedellerinin yüksek olmasıdır. Son yıllarda, programlarından biri de RETScreen teknolojik gelişmelerle birlikte rüzgar programıdır. Türkiye'de birçok araştırmacı enerjisinden elektrik enerjisi üretimi için çalışmalarında RETScreen programını kurulacak santrallerin kurulum, işletme maliyetleri düşüş göstermektedir ve rüzgar enerjisi kullanma eğilimi artmıştır. Literatürde, farklı alanlarda kullanılmak üzere rüzgar enerjisinden elektrik enerjisi elde etmeye yönelik çeşitli çalışmalar bulunmaktadır. Özdamar (2000), İzmir'de bir evin elektrik enerjisi ihtiyacını belirleyip bu ihtiyacın rüzgar enerjisiyle karşılanması ve ekonomik açıdan değerlendirilmesi üzerine bir çalışma yapmıştır. Çalışmasında evin enerji tüketiminin bir günlük planı yapılmış ve bu planın 20 yıl boyunca aynı şekilde tekrarlandığı varsayılmıştır. Yiğit ve Kabul (2014), Isparta yöresinde rüzgar enerjisiyle bir evin elektrik ihtiyacının karşılanması üzerine araştırma yapmışlardır. Yapmış oldukları analizlerde yatırım maliyetleri, işletme giderleri, yıllık kazanç, yıllık fayda, 1skonto vb. parametreler göz önünde bulundurularak dört farklı yöntem kullanmışlardır. Analizler neticesinde 5 kW'llk bir rüzgar türbininin geri ödeme süresi 11 y1l olarak hesaplanmış ve böyle bir yatırımın mantıklı olacağını tespit etmişlerdir. Farklı bir çalışma olarak, Koşar vd. (2015), Kayseri ilinin Pınarbaşı ilçesinin rüzgar potansiyeline uygun olacak 3 metre rotor çapına sahip sabit hızlı küçük ölçekli bir rüzgar türbininin aerodinamik tasarımını gerçekleştirmişlerdir. Aerodinamik tasarımı yapılmış olan türbinin performans eğrilerini elde etmek amacı ile bir kod kullanılmış olup bu bölgede böyle bir tasarımın mekanik ve elektriksel kayıplar olmaksızın yıllık 1295,5 $\mathrm{kWh}$ enerji üreteceğini hesaplamışlardır. Gökçınar ve Uyumaz (2008), rüzgar enerjisi kullanım maliyetleri ve verilen teşvikler üzerine bir araştırma yapmışlardır. Kullanılacak olan rüzgar türbini kapasite faktörünün yatırım maliyetinde çok önemli bir yer tuttuğunu belirtmişlerdir. Ayrıca rüzgar enerji santrallerinin yer, kapasite ve maliyetlerini değerlendirmek üzere bir çok yazılım programı bulunmaktadır. Bu yazılım kullanmaktadır. Akbulut vd. (2009), Türkiye şartlarına uygun rüzgar enerji santrali projelerinin ekonomik analizini RETScreen programı kullanarak yapmışlardır. Analizleri sonucunda yönetmeliklerin öngördüğü minimum şartlar altında ekonomik bir yatırım olması için en az 5 MW'lık bir rüzgar enerji santralinin kurulması gerektiğini belirlemişlerdir. Doğan vd. (2012), Hatay’da kurulacak bir rüzgar enerjisi santrali için RETScreen program ile fizibilite analizi yapmışlardır. 1, 5 ve $10 \mathrm{MW}$ güçlerindeki 3 adet RES projeleri için ekonomik açıdan 2 MW ve üzeri kapasiteli RES yatırımlarının tercih edilebilir olduğunu tespit etmişlerdir. Kaya vd. (2016), Samsun 19 Mayıs ilçesi Yörükler mahallesinde kurulabilecek bir rüzgar enerji santrali için fizibilite analizi yapıp geri ödeme sürelerini belirlemişlerdir. 1, 2, 5 ve $10 \mathrm{MW}$ kapasiteli RES projelerinin analizleri sonucunda geri ödeme sürelerinin sirasiyla $6,4,2,5$ ve 2 yıl olduğunu belirlemişlerdir. RETScreen programı kullanılarak yapılan bir diğer çalışma, Taşkın (2013) tarafından gerçekleştirilen Niğde ili için rüzgar enerjisi santrallerinin analizleridir. Yapılan çalışmada $50 \mathrm{~m}$ ve üzerindeki yükseklikler için rüzgar enerji santralleri kurulumuna yapilabilecek yatırımın uygun olacağı kanaatine varılmıştır. $\mathrm{Bu}$ çalışmada, Mersin'in rüzgar potansiyelinin yüksek olduğu Mut ve Gülnar ilçelerinde kurulabilecek farklı kapasiteli rüzgar enerji santralleri için analizler yapılmış ve birbirleriyle karşılaştırılmıştır.

\section{Materyal ve Metot}

$\mathrm{Bu}$ çalışmada RETScreen analiz programı kullanılarak Şekil 1'de gösterilen Mersin'in yıllık ortalama rüzgar hızının $8 \mathrm{~m} / \mathrm{s}$ olduğu Mut ilçesinde ve yıllık ortalama rüzgar hızının $7,5 \mathrm{~m} / \mathrm{s}$ olduğu Gülnar ilçesinde uygun lokasyonlara kurulması planlanan rüzgar enerjisi santralleri için fizibilite çalışması yapılmış ve ekonomik açıdan 
değerlendirilerek

karşılaştırılmıştır.

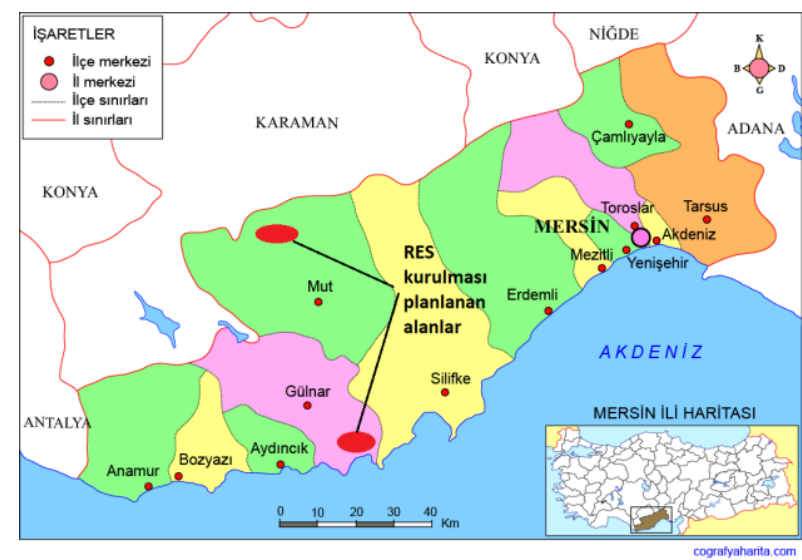

Şekil 1. RES kurulması planlanan alanlar.

\subsection{RETScreen Analiz Programı}

RETScreen Temiz Enerji Proje Analizi Yazılımı ilk kez Kanada Hükümeti CANMET Enerji Araştırma Laboratuvarı tarafından sunulmuştur. RETScreen, çeşitli enerji verimliliği ve yenilenebilir enerji teknoloji türlerinin enerji üretimi ve tasarrufların, emisyon azaltımlarını, finansal uygulanabilirliklerini ve risklerini değerlendirmek üzere dünya çapında kullanılan bir yazılım programıdır (RETScreen, 2018). Bu program ile enerji, maliye, emisyon, finansal ve risk analizleri yapilabilmektedir (Boztepe, 2010). RETScreen analiz program1, girilmesi gereken saha referans koşulları girdisinin, internet veri tabanı ile uyumlu olan iklim veri bankası tarafindan sağlanmasıly otomatik olarak çalışabilen ve Microsoft Excel altyapısına dayanan bir programdır. $\mathrm{Bu}$ program ile iklim veri bankasından enlem, boylam, rakım değerleri, aylara göre hava sıcaklığı, bağıl nem, güneş radyasyonu, atmosferik basınç, rüzgar hızı, yer sıcaklığı, 1sitma ve soğutma değerleri direkt olarak alınabilmektedir (Doğan vd., 2012).
RETScreen programı ile RES Projesi için Fizibilite Analizi basit veya detaylı olarak yapabilmektedir. Programın basit ve detaylı analizindeki farkl1lık, programa santral maliyetlerinin farklı şekilde tanımlanmasıdır. Detaylı analiz ile bütün maliyetlerin teker teker programa tanımlanması sağlanırken; basit analizde bu maliyetler toplu şekilde tanımlanmaktadır. Bu çalışmada Şekil 2'de görüldüğg̈ gibi her iki ilçe için de analiz türü "Seviye 2", iklim referans değerleri; kurulması planlanan ilçelere yakınlığından ve programda tanımlı olmasından ötürü Mersin'in Silifke ilçesi seçilmiştir.

Ekonomik bir RES yatırımı için türbin göbek yüksekliğinde rüzgar hızının $7 \mathrm{~m} / \mathrm{s}^{\text {'den ve }}$ rüzgar kapasite faktörünün $\% 30$ 'dan fazla olduğu yerler tercih edilmelidir (Akbulut vd., 2008). RETScreen'in sunduğu, NASA tarafından belirlenmiş " $10 \mathrm{~m}$ yüksekliğindeki rüzgar hızı" verileri göbek yüksekliğine göre uyarlanmalıdır. Bu bilgilerin yerine ülkemiz Elektrik İşleri Etüt İdaresi tarafindan hazırlanmış olan REPA verileri tercih edilmiştir. Rüzgar Enerjisi Potansiyel Atlası (REPA), orta-ölçekli sayısal hava tahmin modeli ve mikro-ölçekli rüzgar akış modeli kullanılarak üretilen rüzgar kaynak bilgilerinden oluşmaktadır (YEGM, 2018).SSekil 3'de görülen Mersin iline ait REPA haritaları incelendiğinde Mut ve Gülnar ilçelerinin iç kesimlerinde rüzgar hızının, rüzgar santralleri için önerilen değerlere uygun olduğu görülmektedir. Bu çalışmada Mut ilçesinde $50 \mathrm{~m}$ yükseklikte, yıllık ortalama rüzgar hızının $8 \mathrm{~m} / \mathrm{s}$ olduğu ve Gülnar ilçesinde $50 \mathrm{~m}$ yükseklikte, yılllk ortalama rüzgar hızının $7,5 \mathrm{~m} / \mathrm{s}$ olduğu bir alana kurulması planlanan rüzgar enerji santralleri için fizibilite analizi yapılmıştır. 
Mersin İlinin Farklı İlçelerinde Kurulabilecek Rüzgar Enerjisi Santrallerinin RETScreen Programı ile Fizibilite Analizleri ve Karşılaştırılmaları

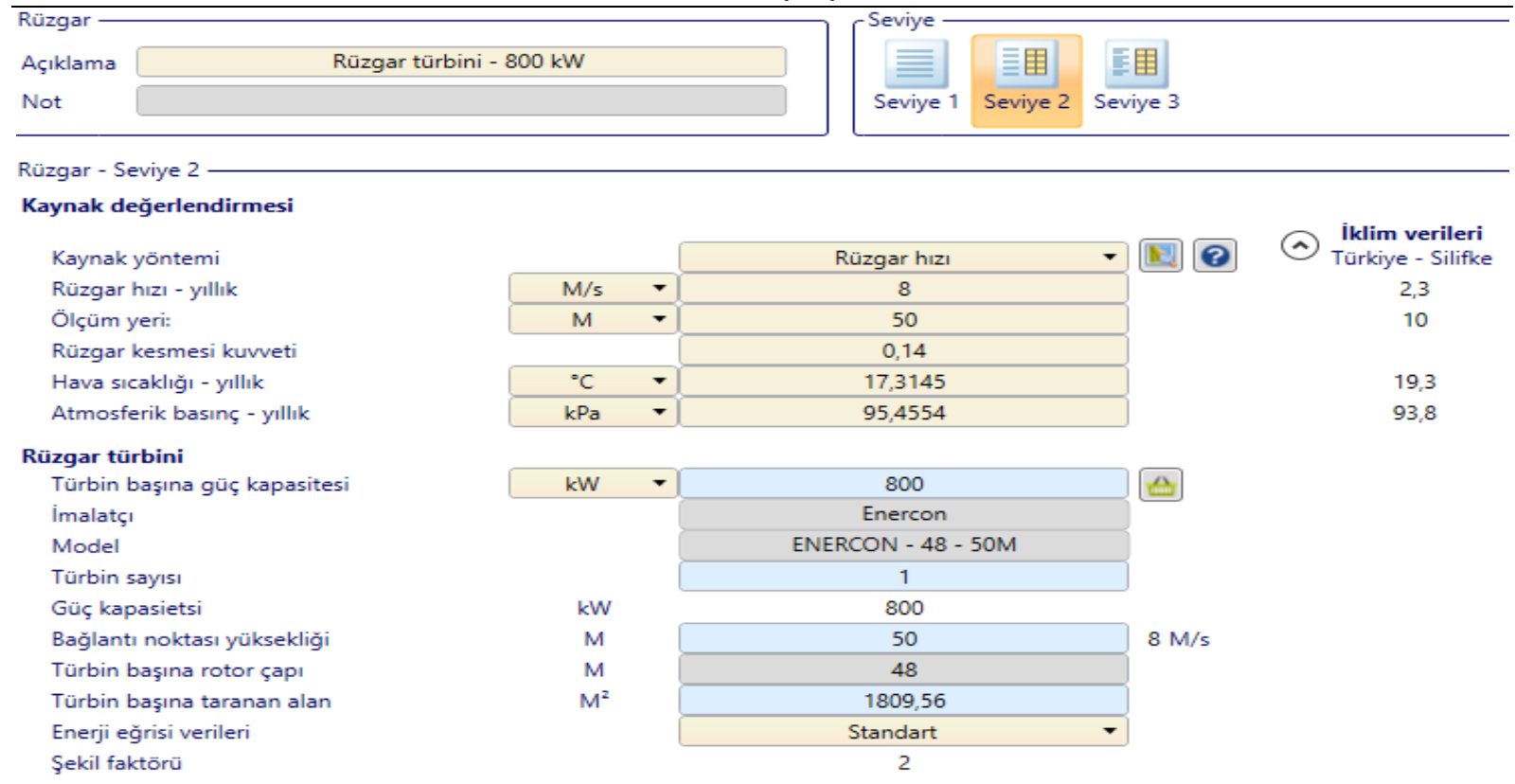

(a)
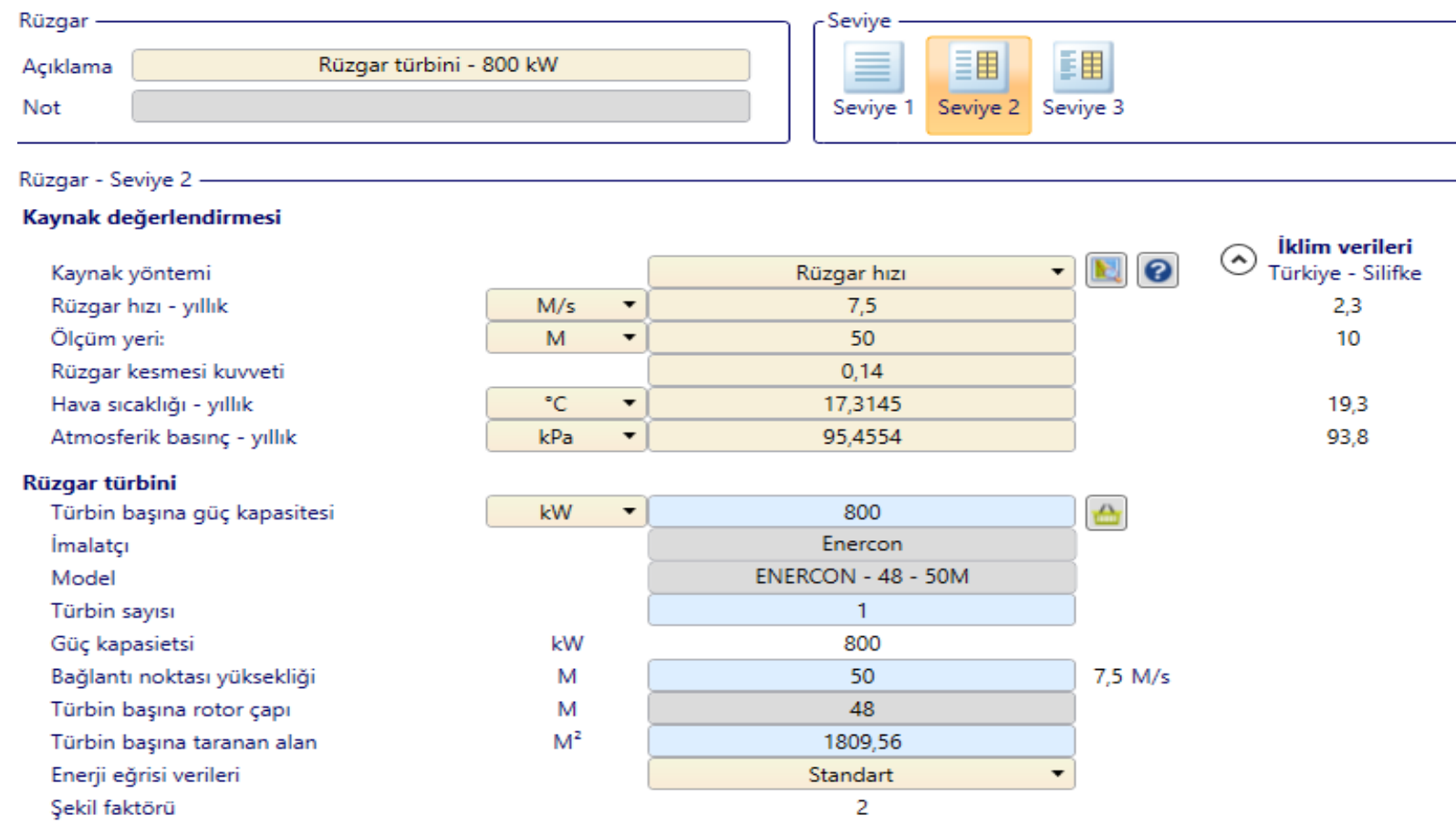

(b)

Şekil 2. (a) Mut (b) Gülnar ilçeleri RES enerji modeli bilgileri.

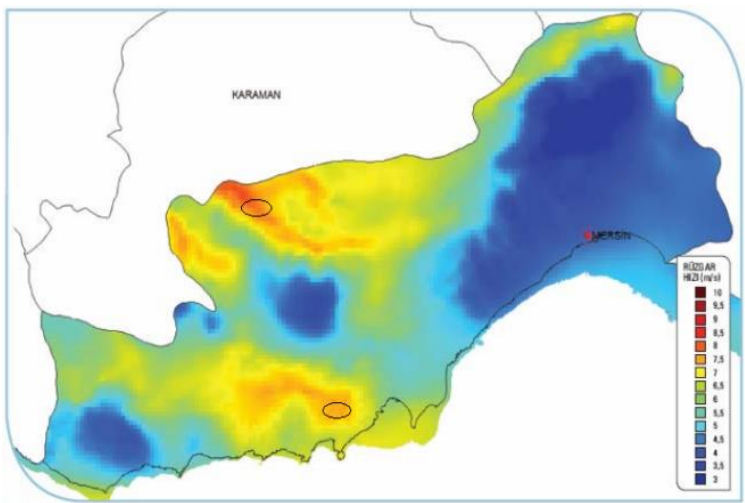

(a)

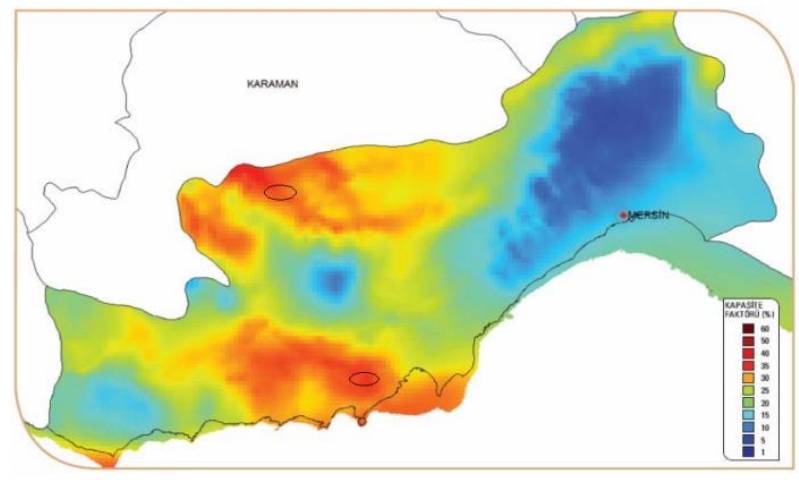

(b)

Şekil 3. REPA Mersin (a) rüzgar hızı dağılımı (b) rüzgar kapasite faktörü (REPA, 2018). 


\subsection{Enerji Modeli}

$\mathrm{Bu}$ modülde analiz için öncelikle kullanılacak olan türbin tipi seçilerek, bu türbinden alınabilecek yıllık maksimum enerji miktarı hesaplanır. Türbin seçimi ve türbinin tüm spesifik özellikleri, RETScreen programı ile entegre halde bulunan ürün veri tabanından yapılır. $\mathrm{Bu}$ çalışmada, $50 \mathrm{~m}$ göbek yüksekliğinde bulunan $800 \mathrm{~kW}$ gücündeki Enercon-48-50M türbini seçilmiş olup Mut ve Gülnar ilçelerinde kurulmak üzere 1,5 ve 10 adet türbin kullanımı için analizler yapılmıştır. Tablo 1 ve Şekil 4'de sunulan, türbin güç ve enerji eğrisi verileri program tarafindan otomatik olarak oluşturulmuştur.

Tablo 1. Seçilen türbinin güç ve enerji eğrisi verileri.

\begin{tabular}{|c|c|c|}
\hline $\begin{array}{l}\text { Rüzgar } \\
\operatorname{Hız1}(\mathrm{m} / \mathrm{s})\end{array}$ & $\begin{array}{l}\text { Güç Eğrisi } \\
\text { Verileri (kW) }\end{array}$ & $\begin{array}{l}\text { Enerji Eğrisi } \\
\text { Verileri (MWh) }\end{array}$ \\
\hline $0-2$ & 0 & \\
\hline 3 & 5 & 193 \\
\hline 4 & 25 & 524 \\
\hline 5 & 60 & 1030 \\
\hline 6 & 110 & 1645 \\
\hline 7 & 180 & 2283 \\
\hline 8 & 275 & 2884 \\
\hline 9 & 400 & 3421 \\
\hline 10 & 555 & 3884 \\
\hline 11 & 671 & 4271 \\
\hline 12 & 750 & 4583 \\
\hline 13 & 790 & 4821 \\
\hline 14 & 810 & 4989 \\
\hline 15 & 810 & 5093 \\
\hline 16-30 & 810 & \\
\hline
\end{tabular}

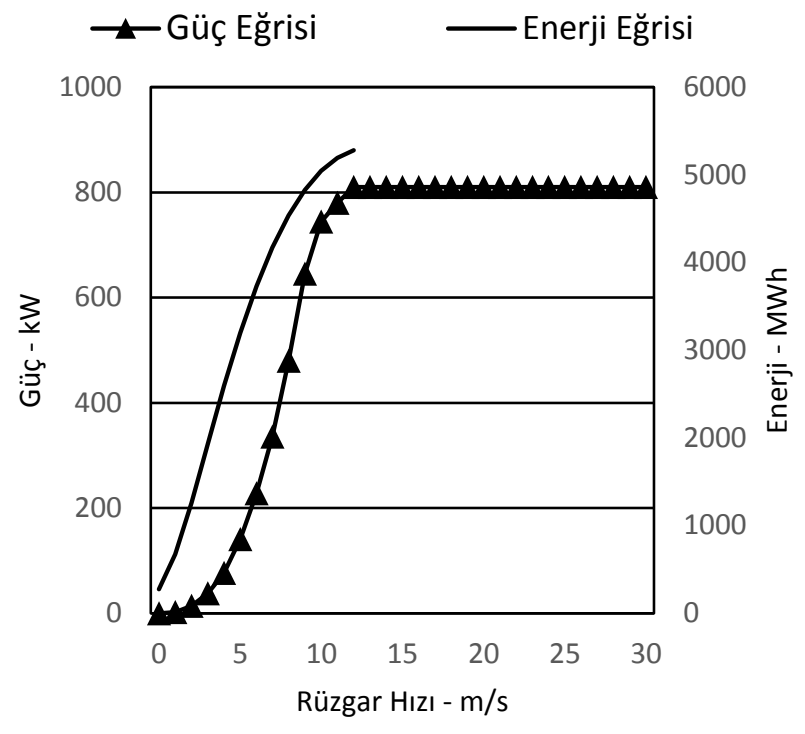

Şekil 4. Seçilen türbinin güç ve enerji eğrisi.

RES uygulamalarında bir türbinin rüzgardaki enerjiyi elektrik enerjisine dönüştürebilme oranı olarak tanımlanan Kapasite faktörü genellikle $\% 25$ ile $\% 35$ arasında değişmektedir (Koşar vd., 2015). Bu çalışmada rüzgar hızına bağlı olarak kapasite faktörü Mut ilçesinde \%34,7; Gülnar ilçesinde \%31,1 olarak program tarafindan belirlenmiştir. Kullanılacak türbin adedine ve kurulacak bölgelere göre şebekeye verilen yıllık elektrik miktarı Tablo 2'de sunulmuştur.

Tablo 2. Türbin sayısına göre şebekeye verilen elektrik gücü.

\begin{tabular}{|c|c|c|c|}
\hline Türbin & $\begin{array}{c}\text { Kurulu } \\
\text { Güç } \\
\text { Sayı1 }\end{array}$ & $\begin{array}{c}\text { Şebekeye } \\
\text { Verilen } \\
\text { Elektrik } \\
\text { (MWh) }\end{array}$ & $\begin{array}{c}\text { Şebekeye } \\
\text { Verilen } \\
\text { Elektrik } \\
\text { (MWh) }\end{array}$ \\
\cline { 3 - 4 } & & Mut & Gülnar \\
\hline 1 & 0,8 & 2434 & 2180 \\
\hline 5 & 4 & 12170 & 10900 \\
\hline 10 & 8 & 24339 & 21801 \\
\hline
\end{tabular}

$\mathrm{Bu}$ modülde yapılması gereken son işlem elektrik satış fiyatının girilmesidir. Programın enerji modeli sayfasında elektrik satış fiyatı tarafımızdan 29 \$/MWh olarak girilmiștir. EPDK'nın 13/12/2017 tarihli kurul kararında belirttiği üzere yenilenebilir enerji kaynaklı elektrik üretim santrallerinin Türkiye ortalama elektrik toptan satış fiyatı $17,1 \mathrm{Krş/kWh'dır.} \mathrm{Bu}$ değer ise yaklaşık 
Mersin İlinin Farklı İlçelerinde Kurulabilecek Rüzgar Enerjisi Santrallerinin RETScreen Programı ile Fizibilite Analizleri ve Karşılaştırılmaları

olarak girmiş olduğumuz 29 \$/MWh'a denk santraller için detaylı maliyet analizi gelmektedir.

\subsection{Maliyet Analizi}

Programda Mut ve Gülnar ilçelerinde 1, 5 ve yapılmıştır. Bu analizlerden Mut ilçesinde 1 türbin kullanılarak yapılan analiz, örnek olarak Şekil 5'de gösterilmiştir.

10 adet türbin kullanılarak inşası planlanan

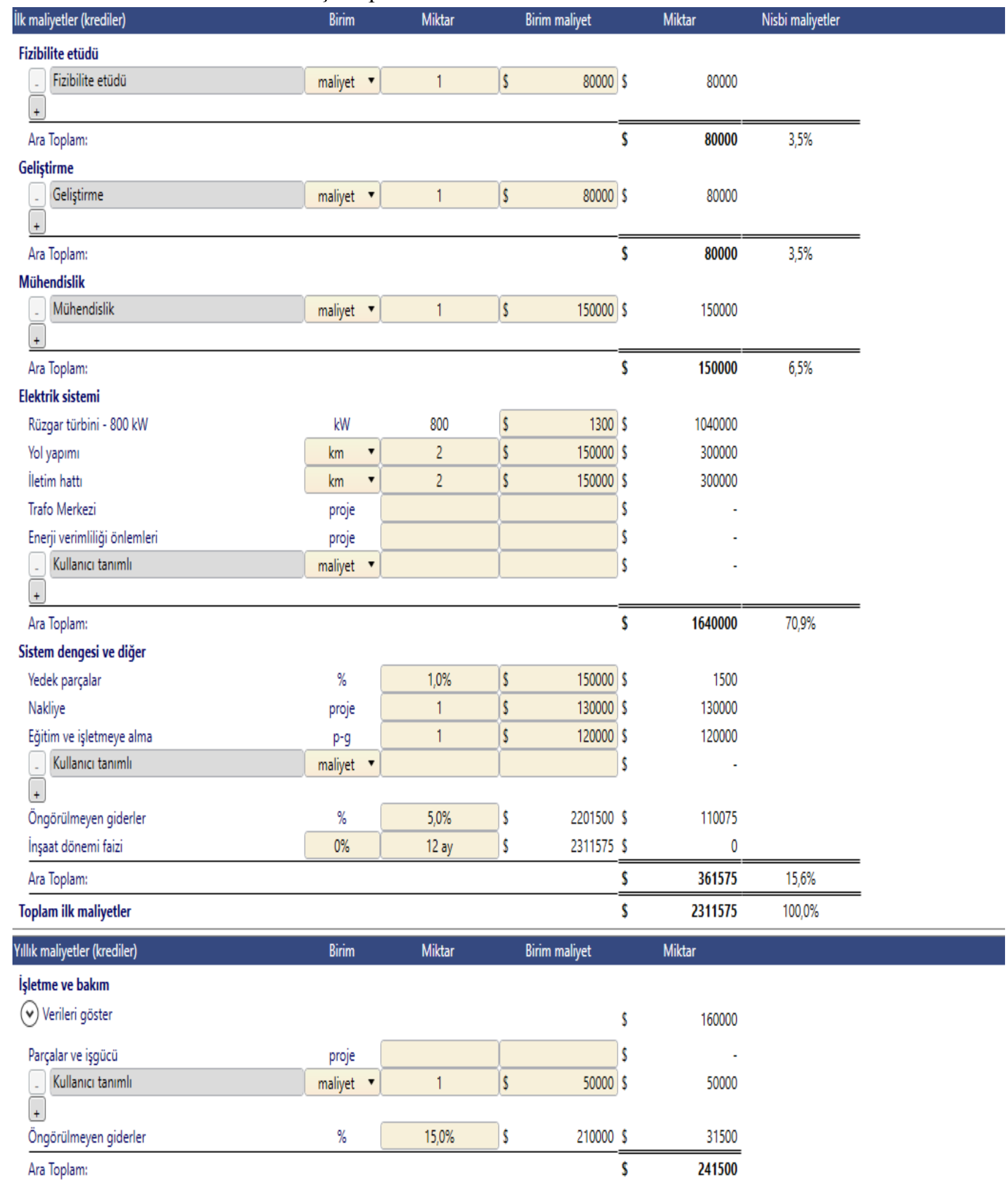

Şekil 5. Detaylı maliyet analizi tablosu. 

Analizleri ve Karşılaştırılmaları

Mut ve Gülnar ilçeleri için kullanılan türbin maliyet analizi, her iki ilçe için de RES sayısına göre toplam maliyet ve toplam kurulumda maliyetin aynı olmasından dolayı maliyetin içerisinde yer alan gider tek bir tabloda belirtilmiştir (Tablo 3).

başlıklarının yüzdesel oranlarını içeren

Tablo 3. Türbin sayısına göre maliyet analizi.

\begin{tabular}{lccc}
\hline Türbin Sayıs1 & 1 Türbin & 5 Türbin & 10 Türbin \\
\hline Kurulu Güç & $800 \mathrm{~kW}$ & $4000 \mathrm{~kW}$ & $8000 \mathrm{~kW}$ \\
\hline Toplam Maliyet (\$) & 2311575 & 6679575 & 12139575 \\
\hline Fizibilite Etüdü (\%) & 3,5 & 1,2 & 0,7 \\
\hline Geliştirme (\%) & 3,5 & 1,2 & 0,7 \\
\hline Mühendislik (\%) & 6,5 & 2,2 & 1,2 \\
\hline Elektrik Sistemi (\%) & 70,9 & 86,8 & 90,6 \\
\hline Sistem Denge-Diğer (\%) & 15,6 & 8,5 & 6,8 \\
\hline Yillik Maliyetler (\$) & 241500 & 977500 & 1897500 \\
\hline
\end{tabular}

\subsection{Emisyon Analizi}

Yenilenebilir enerji kaynakları, yeryüzünde ve doğada çoğunlukla herhangi bir üretim sürecine ihtiyaç duymadan temin edilebilen, kömür ve petrol gibi fosil kaynaklı olmayan, elektrik enerjisi üretilirken $\mathrm{CO}_{2}$ emisyon miktarı düşük doğa dostlarıdır. Geleneksel enerji kaynaklarına kıyasla çevreye verdikleri zarar çok daha düşüktür. Emisyon azalımı RES yatırımcısını direkt olarak etkilemese de yapılan yatırımın sonucunda toplumsal ve çevresel kazanımları ifade eden veriler Tablo 4'de gösterilmiştir.

Tablo 4. Emisyon analizi.

\begin{tabular}{llllll}
\hline $\begin{array}{l}\text { Kurulu } \\
\begin{array}{l}\text { Güç } \\
(\mathrm{MW})\end{array}\end{array}$ & Konum & $\begin{array}{l}\text { Yillık Elektrik } \\
\text { Üretim Miktarı } \\
(\mathrm{MWh})\end{array}$ & $\begin{array}{l}\text { Y1llık Sera Gazı } \\
\text { Emisyon Azalmas1 } \\
\left(\mathrm{tCO}_{2}\right)\end{array}$ & $\begin{array}{l}\text { Tüketilmeyen Ham } \\
\text { Petrol Varili }\end{array}$ & $\begin{array}{l}\text { Geri } \\
\text { Kazanılan } \\
\text { Atık (t) }\end{array}$ \\
\hline & Mut & 2434 & 1147,6 & 2669 & 395,7 \\
0,8 & Gülnar & 2180 & 1027,9 & 2391 & 354,5 \\
\hline & Mut & 12170 & 5738,1 & 13344 & 1978,6 \\
4 & Gülnar & 10900 & 5139,6 & 11953 & 1772,3 \\
\hline & Mut & 24339 & 11476,1 & 26689 & 3957,3 \\
8 & Gülnar & 21801 & 10279,2 & 23905 & 3544,6 \\
\hline
\end{tabular}

\subsection{Ekonomik Analiz}

Programın ekonomik analiz kısmı Finansal Parametreler, Yıllık Gelir, Proje Maliyetleri ve Gelir Özeti, Finansal Sürdürülebilirlik ve Y1llık Nakit Akışı olmak üzere beş bölümden oluşmaktadır. "Proje Maliyetleri ve Gelir Özeti" ile "Y1llık Gelir" bölümleri; enerji modeli, maliyet analizi ve emisyon analizi çalışma sayfalarının özeti niteliğindedir. Kullanıcının "Finansal Parametreler" bölümüne girmiş olduğu verileri kullanılarak projenin finansal göstergelerini oluşturan bölüm "Finansal Sürdürülebilirlik" bölümüdür. Kullanıcının vergi öncesi, vergi sonrası ve toplam nakit akışını görüntülemesini sağlayan bölüm ise "Y1llık
Nakit Akışı" bölümüdür. $\mathrm{Bu}$ çalışmada yatırımın tamamının öz sermaye ile yapılacağı, santral ömrünün 20 yıl olduğu kabul edilmiş; Türkiye şartları için yıllık enflasyon oran $1 \% 10,3$, yıllık gelir vergisi oran $\% 35$, elektrik ihracat fiyatı eskalasyon oranı \%11 olarak alınmıştır (Hazine Müsteşarlığı, $\quad$ 2018). $\mathrm{Bu}$ çalışmada, kullanılmak üzere seçilen türbinler için projenin nakit akışlarına Şekil 6'da yer verilmiştir. Projenin kümülatif nakit akışı genellikle negatif değerlerden başlayarak yıllar içinde artmakta ve pozitif değerler almaktadır. Kümülatif nakit akışının 0 değerini alması ise projenin başabaş 
Mersin İlinin Farklı İlçelerinde Kurulabilecek Rüzgar Enerjisi Santrallerinin RETScreen Programı ile Fizibilite Analizleri ve Karşılaştırılmaları

noktasını göstermektedir. $\mathrm{Bu}$ çalışmada Mut sayılarına ait projelerin geri ödeme ve Gülnar ilçeleri için seçilen 1, 5 ve 10 adet sürelerinin Mut için sırasıyla 5, 3,5 ve 3 yıl; türbinin kümülatif nakit akışları Gülnar için sırasıyla 6, 4 ve 3,5 yıl olduğu değerlendirildiğinde söz konusu türbin tespit edilmiştir.

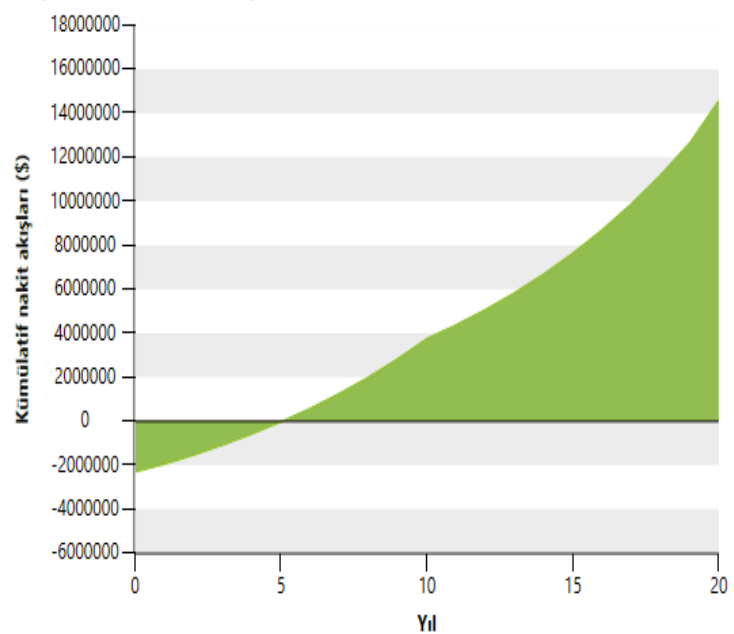

(a) Mut'ta 0,8 MW kapasiteli RES.

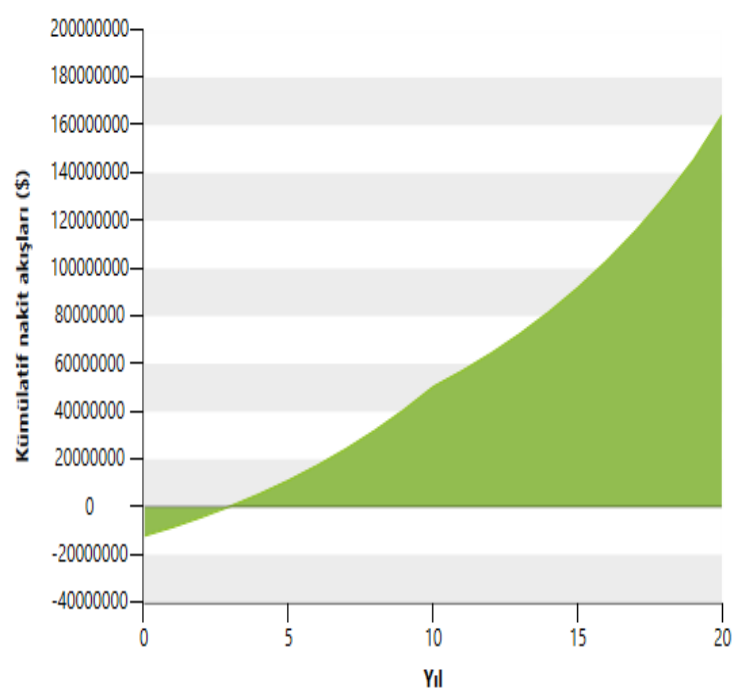

(c) Mut'ta 8 MW kapasiteli RES.

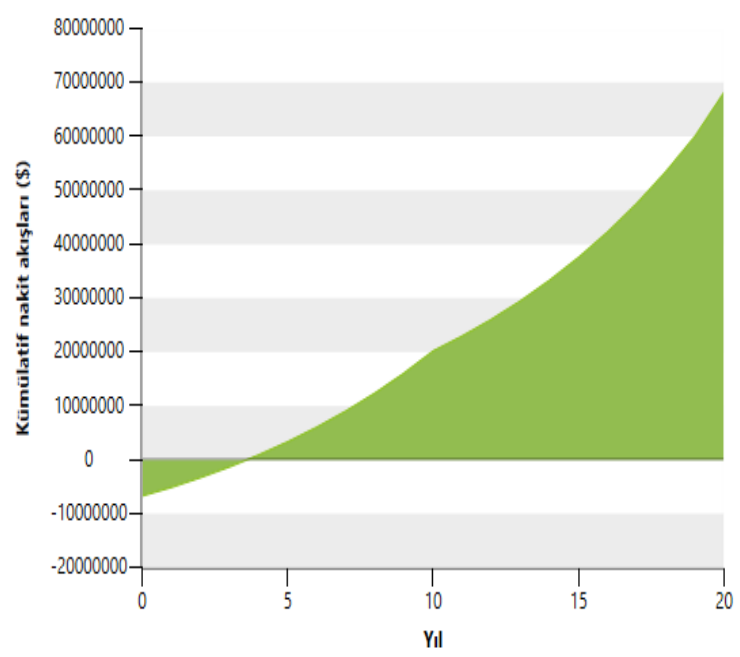

(e) Gülnar'da 4 MW kapasiteli RES.

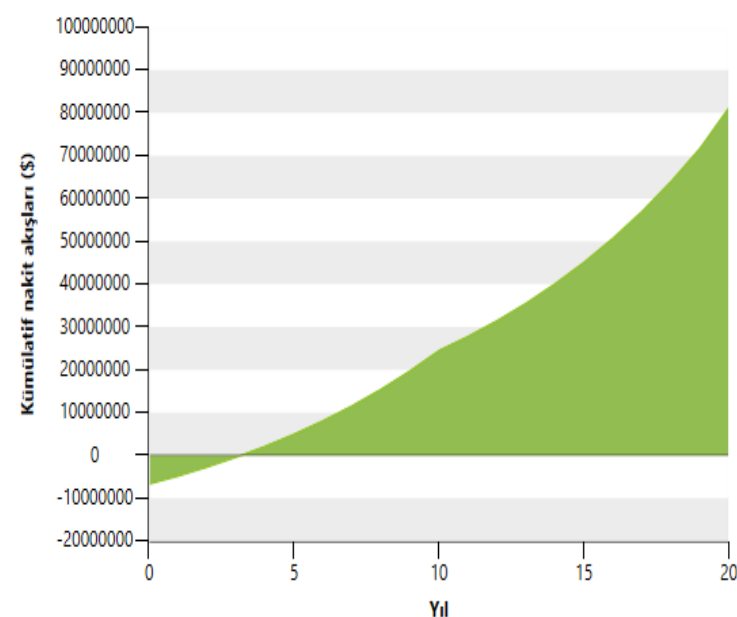

(b) Mut'ta 4 MW kapasiteli RES.

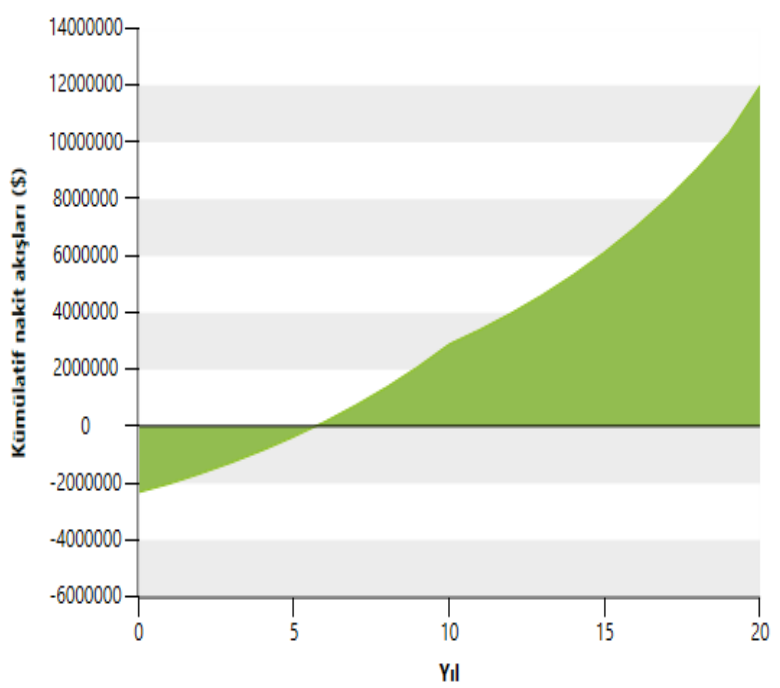

(d) Gülnar'da 0,8 MW kapasiteli RES.

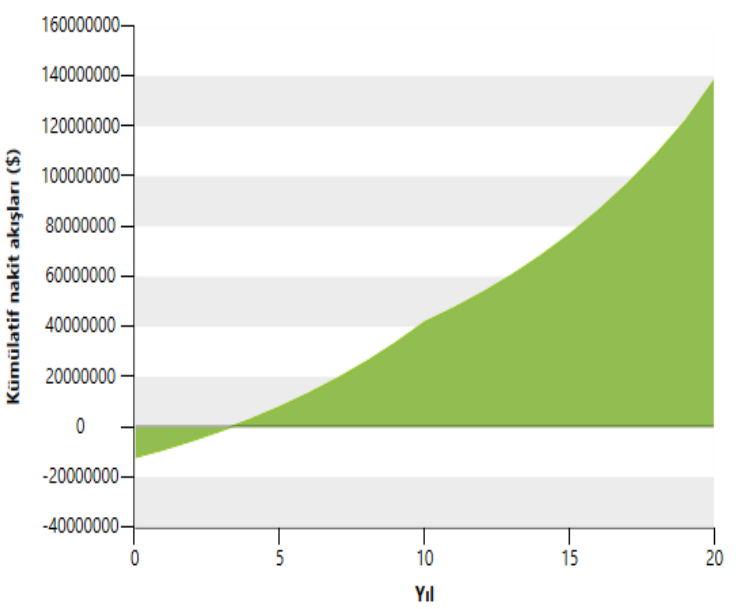

(f) Gülnar'da 8 MW kapasiteli RES.

Şekil 6. Mut (a),(b),(c) ve Gülnar (d),(e),(f) ilçelerinde kurulacak farklı güçteki RES'ler için yıllık nakit akışları. 
$\mathrm{Bu}$ fizibilite çalışmasında RETScreen Şekil 7'de örnek gösterim olarak Mut programı ile finansal parametreler, maliyet ilçesinde $0,8 \mathrm{MW}$ kurulu güç için yapılan ve tasarruflar, yıllık nakit akışları, yıllık ciro analiz sunulmuştur. ve finansal sürdürülebilirlik elde edilmiştir.

\begin{tabular}{|c|c|c|c|c|c|c|c|c|c|}
\hline \multicolumn{3}{|l|}{ Finansal parametreler } & \multicolumn{3}{|l|}{ Maliyetler | Tasarruflar | Hasilat } & \multicolumn{4}{|c|}{ Yıllık nakit akışlan } \\
\hline Genel & & & illk maliyetler & & & Yil & Vergi öncesi & Vergi sonrası & Kümülatif \\
\hline Enflasyon oranı & $\%$ & $10 \%$ & Fizibilite etüdü & $\$$ & 80000 & $\#$ & $\$$ & $\$$ & $\$$ \\
\hline İskonto oranı & $\%$ & $10 \%$ & Geliştirme & $\$$ & 80000 & 0 & -2311575 & -2311575 & -2311575 \\
\hline Proje ömrü & yll & 20 & Mühendislik & $\$$ & 150000 & 1 & 517436 & 356560 & -1955015 \\
\hline & & & Elektrik sistemi & $\$$ & 1640000 & 2 & 576984 & 414481 & -1540534 \\
\hline \multicolumn{3}{|l|}{ Finansman } & & & & 3 & 643347 & 455645 & -1084890 \\
\hline Teşvikler ve hibeler & s & & Sistem dengesi ve diğer & $\$$ & 361575 & 4 & 717299 & 501840 & -583050 \\
\hline Borç oranı & $\%$ & $0 \%$ & \multirow{3}{*}{$\begin{array}{l}\text { Toplam ilk maliyetler } 100 \% \\
\text { Yıllık maliyetler ve borç ödemeleri }\end{array}$} & \multirow[t]{3}{*}{$\$$} & \multirow{3}{*}{2311575} & 5 & 799705 & 553624 & -29426 \\
\hline & \multirow{2}{*}{\multicolumn{2}{|c|}{$\checkmark$}} & & & & 6 & 891526 & 611617 & 582191 \\
\hline Gelir vergisi analizi & & & & & & 7 & 993834 & 676511 & 1258702 \\
\hline Geçerli gelir vergisi oranı & $\%$ & $35 \%$ & \multirow{2}{*}{ işletme ve bakım } & \multirow[t]{2}{*}{$\$$} & \multirow[t]{2}{*}{241500} & 8 & 1107821 & 749076 & 2007779 \\
\hline Zarar beyanı? & \multirow{2}{*}{\multicolumn{2}{|c|}{ Azalan denge }} & & & & 9 & 1234813 & 830172 & 2837951 \\
\hline Amortisman yöntemi & & & Toplam yillık maliyetler & \multirow[t]{2}{*}{$\$$} & \multirow[t]{2}{*}{241500} & 10 & 1376289 & 920754 & 3758705 \\
\hline Yari yil kuralı - yil 1 & evet/hayır & Evet $\mathbf{V}$ & Yillık tasarruflar ve gelir & & & 11 & 918326 & 621770 & 4380474 \\
\hline Amortisman vergi matrahı & $\%$ & $100 \%$ & \multirow{2}{*}{ Elektrik ihraç geliri } & \multirow[b]{2}{*}{$\$$} & \multirow{2}{*}{486787} & 12 & 1026232 & 690666 & 5071140 \\
\hline Amortisman oranı & $\%$ & $5 \%$ & & & & 13 & 1146697 & 767787 & 5838928 \\
\hline Vergi tatili var mı? & evet/hayır & Hayır $\mathbf{v}$ & || SG azaltım geliri - 10 yıl & $\$$ & 803 & 14 & 1281171 & 854074 & 6693002 \\
\hline & & Haylr & Diğer gelir (maliyet) - 20 yll & $\$$ & 23200 & 15 & 1431271 & 950573 & 7643575 \\
\hline \multicolumn{3}{|l|}{ Yillik ciro } & & $\$$ & 194715 & 16 & 1598799 & 1058454 & 8702028 \\
\hline Elektrik ihraç geliri & & & \multirow{2}{*}{ Toplam yıllık tasarruflar ve gelir } & $\$$ & 705505 & 17 & 1785764 & 1179019 & 9881047 \\
\hline Şebekeye verilen elektrik & $M W h \bullet$ & 2434 & & & 年 & 18 & 1994404 & 1313722 & 11194769 \\
\hline Elektrik ihracat fiyatı & $\$ / \mathrm{kWh} \quad \mathbf{V}$ & 0,20 & Finansal sūrdūrūlebilirlik & & & 19 & 2227216 & 1464181 & 12658951 \\
\hline Elektrik ihraç geliri & s & 486787 & Vergi öncesi IGO - özsermaye & & & 20 & 2486979 & 1929869 & 14588820 \\
\hline Elektrik ihracatı eskalasyon oranı & $\%$ & $\begin{aligned} 480 / 8 / \\
11 \%\end{aligned}$ & Vergi öncesi IGO - varlıklar & $\%$ & $317 \%$ & & & & \\
\hline & & & & & & & & & \\
\hline SG azaltım geliri & & & Vergi sonrası IGG - özsermaye & $\%$ & $23,5 \%$ & & & & \\
\hline Net seragazı azaltımı & $\mathrm{tCO}_{2} / \mathrm{yll}$ & 1148 & Vergi sonrası IGO - varlıklar & $\%$ & $23,5 \%$ & & & & \\
\hline Net seragazı azaltımı - $20 \mathrm{yl}$ & $\mathrm{tCO}_{2}$ & 22952 & & & & & & & \\
\hline Seragazı azaltma kredi oranı & $\$ / \mathrm{tCO}_{2}$ & 0,70 & Basit geri ödeme & yll & 5 & & & & \\
\hline SG azaltım geliri & $s$ & 803 & Özsermaye geri ödeme & yll & 5 & & & & \\
\hline Seragazı azaltma kredi süresi & yll & 10 & Net Şimdiki Değer (NPV) & $\$$ & 3471907 & & & & \\
\hline Net seragazı azaltımı - $10 \mathrm{yll}$ & $\mathrm{tCO}_{2}$ & 11476 & Yillık yaşam döngüsü tasarrufları & $\$ / y \mid$ & 407809 & & & & \\
\hline Seragazı azaltma kredi eskalasyon oranı & $\%$ & $8 \%$ & & & & & & & \\
\hline Diğer gelir (maliyet) & & & $\begin{array}{l}\text { Maliyet-Fayda oranı } \\
\text { Borç cevrilebilirliği }\end{array}$ & & $\begin{array}{r}2,5 \\
\text { Borcyok }\end{array}$ & & & & \\
\hline Enerji & $\mathrm{MWh}-$ & 800 & 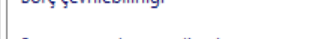 & & 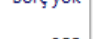 & & & & \\
\hline Fiyat & $\$ / M W h \quad v$ & 29 & Seragazı azaltma maliyeti & $\$ / \mathrm{tCO}_{2}$ & -355 & & & & \\
\hline Diğer gelir (maliyet) & s & 23200 & Enerji üretim maliyeti & $\$ / \mathrm{kWh}$ & 0,397 & & & & \\
\hline Süre & yll & 20 & & & $E$ & & & & \\
\hline Eskalasyon oranı & $\%$ & $11 \%$ & & & & & & & \\
\hline
\end{tabular}

Temiz Enerji (TE) üretim geliri

TE üretimi

TE üretim kredi oranı

TE üretim geliri

TE üretim kredi süresi

TE üretim kredi eskalasyon oranı

Yakıt türü
Rüzgar

Şekil 7. Ekonomik analiz bilgileri.

\section{Sonuç ve Tartışma}

Tüm yatırımlar anaparanın bankada değerlendirilmesiyle elde edilecek kazanca göre daha avantajlı olmalıdır. Üretime yapılan yatırım beraberinde büyük sorumluluk ve riskler de getirmektedir. Kazanımlar değerlendirilirken bu ayrıntılar da göz önünde bulundurulur. Bu çalş̧mada Mersin'in Mut ve Gülnar ilçeleri için RETScreen programı kullanılarak farklı kurulu güçlerde yapılacak olan rüzgar enerji santrali yatırımlarını fizibilite analizi yapılmış ve birbirleriyle karşılaştırılmıştır. Rüzgar türbini göbek yüksekliği $50 \mathrm{~m}$, Mut'un yıllık ortalama rüzgar hızı $8 \mathrm{~m} / \mathrm{s}$ ve kapasite faktörü \%34,7; Gülnar'ın ise ylllık ortalama rüzgar hızı $7,5 \mathrm{~m} / \mathrm{s}$ ve kapasite 
faktörü \%31,1 olarak seçilmiştir. Yapılan çalışmada Mut ve Gülnar ilçelerinde farklı sayıda 800 kW'lık Enercon-48-50M türbini değerlendirilmiş olup Mut için; 1 adet türbinin 5 yılda, 5 adet türbinin 3,5 yılda, 10 adet türbinin 3 yılda Gülnar için ise; sırasıyla 5,5, 4 ve 3,5 y1lda kendini amorti edebileceği belirlenmiştir. Mut ve Gülnar'da verilen şartlarda RES kurulduğunda yatırımcının 20 yılın sonunda elde ettiği kazanım, anaparasının bankada değerlendirilmesiyle elde edilecek olan miktardan çok daha yüksektir. Ancak Mut'un y1llık ortalama rüzgar hızı değerinin Gülnar'dan daha yüksek olması nedeniyle yapılacak yatırım yerinin Mut olarak seçilmesi daha uygundur. Ayrica program tarafindan yapılan analizlere göre Mut'ta kurulacak her $0,8 \mathrm{~kW}$ 'lik enerji santralinin y1llik net 1147,6 ton $\mathrm{CO}_{2}$ gazı salınımı önlediği ve 2669 adet eş değer ham petrolün tasarruf edilmesine katkıda bulunduğu tespit edilmiştir.

\section{Kaynaklar}

Akbulut, U., Doğan, B.T., Kıncay, O. 2008. Ülkemizde Rüzgar Enerjisi Başvuruları Gerekçe, Usul ve Bazı Gerçekleri. IV. Ege Enerji Sempozyumu, 43-52, Ege Üniversitesi, İzmir.

Boztepe, A.A. 2010. Risk Yönetimi Temelli Rüzgar Enerjisi Ekonomisi. Yüksek Lisans Tezi, Yıldız Teknik Üniversitesi, Fen Bilimleri Enstitüsü, İstanbul.

Doğan, B.T., Çolakoğlu, A., Kıncay, O. 2012. RETScreen Analiz Programı ile Hatay'da Rüzgar Enerji Santrali Fizibilite Analizi. Türk Mühendis ve Mimar Odaları Birliği, Makine Mühendisleri Odası, 131, 22-27.

Gökçınar, R.E., Uyumaz, A. 2008. Rüzgar Enerjisi Maliyetleri ve Teşvikleri. VII. Ulusal Temiz Enerji Sempozyumu, UTES'2008, 17-19.

Kaya, K., Koç, E., Okumuş, Ö.Z. 2016. Samsun 19 mayis ilçesi yörükler mahallesine kurulabilecek rüzgar türbin santrali için fizibilite analizi. 1st Internatonal Mediterranean Science and Engineering Congress (IMSEC), Adana, 672, 2322-2330.

Koşar, O., Genç, M.S., Özkan, G., Karasu, İ. 2015. Kayseri Pınarbaşı Rüzgar potansiyeline uygun Küçük Ölçekli Rüzgar Türbini aerodinamik tasarımı. İzmir Rüzgar Sempozyumu, İzmir.

Özdamar, A. 2000. Dünya ve Türkiye'de rüzgar enerjisinden yararlanılması üzerine bir araştırma. Pamukkale Üniversitesi Mühendislik Bilimleri Dergisi, 6(2), 133-145.

Taşkın, B. 2013. Niğde İlinde Kurulabilecek Rüzgar Enerji Santralinin Fiziksel ve Ekonomik Analizi. Yüksek Lisans Tezi, Niğde Üniversitesi, Fen Bilimleri Enstitüsü, Niğde.

URL-1, T.C. Başbakanlık Hazine Müsteşarlığı. Son erişim tarihi: 20/04/2018 https://www.hazine.gov.tr/

URL-2, Rüzgar enerjisi potansiyel atlası. Son erişim tarihi: 20/04/2018 http://www.yegm.gov.tr/

URL-3, Natural Resources Canada. Son erişim tarihi: 20/04/2018 http://www.retscreen.net

Yiğit, F., Kabul, A. 2014. Isparta Yöresinde Bir Evin Elektirik İhtiyacının Rüzgar Enerjisi İle Karşılanmasının Ekonomik Analizi. Makine Teknolojileri Elektronik Dergisi, 11(2), 1-9. 